\title{
Understanding Co-Working with The Growth and Development of Freelancers
}

\author{
Jeffrey M. Shepard ${ }^{1, *}$ \\ ${ }^{1}$ Entrepreneur In Residence Faculty, MA in Management, Saybrook University, USA \\ *Correspondence: Entrepreneur In Residence Faculty, MA in Management, Saybrook University, USA. Tel: \\ 1-585-237-8382. E-mail: jshepard@saybrook.edu
}

Received:March 26, $2018 \quad$ Accepted: April 11, $2018 \quad$ Online Published: April 13, 2018

doi:10.5430/mos.v5n2p1

URL: https://doi.org/10.5430/mos.v5n2p1

\begin{abstract}
The global workplace is changing, and co-working is growing up considerably in this new workspace. In the $21^{\text {st }}$ century, co-working spaces are growing rapidly, and it is expected that by 2020 , freelancers who use these spaces will make up $50 \%$ of the total workforce. When they first started, they were viewed as being ideal for creatives, or people who were looking to start out their businesses. As the freelancing world continues to evolve, more people from all professions are making use of it.

This paper shall look at this development in co-working, and the results which reveal that there is growth for freelancers. These are spaces that are forming a new section of the economy, especially when it comes to making the most of the digital economy as well as the knowledge economy. In this paper, an in-depth review has been carried out, and there is a qualitative study of freelances who are making use of co-working spaces. It seeks to understand the reasons that these spaces are helping to elevate growth, as well as the development of freelancers.

It has been revealed that the key reason co-working continues to be a primary choice for freelancers is the cost effectiveness, as it is lower in cost than setting up a business. In addition, it helps with building social relationships within the work place, without any stress linked with maintaining these relationships. What was once perfect for creatives, is now available for all types of freelancers.
\end{abstract}

Keywords: freelancers, co-working, self-employment, employment solutions

\section{Introduction}

All around the world there are significant changes that have occurred in the working environment. People are seeking to have full control of their lives, both personally and professionally. For that reason, they are looking more into self-employment and management so that they can grow. However, the path to being self-employed can be particularly challenging, especially when one considers the associated costs. Those who choose this path, find that they need to pay certain expenses when they are creating their new enterprises. The highest of these costs is often that of setting up some premises, renting out the space and getting all the equipment that is necessary.

With the mindset that one cannot achieve a successful business without having this in place, many people then shy away from creating their own enterprises. Instead, they choose to work without an infrastructure, as freelancers who share their services while primarily operating from their lap top or desktop computers. Freelancers are highly independent, and are individuals who work for themselves or they own small businesses. They will normally work remotely, and can be self-employed or in some cases, they are contracted by an organisation to offer services.

Although most of them will work from their homes, they also use a range of different areas based on the services that they offer. For example, a freelance seeking access to Wi-Fi may choose to operate from a coffee shop or even a library to gain access to the resources they need in the most affordable way. This is where co-working comes in as the ideal solution for freelancers who are looking to grow and succeed.

A quick way to understand why freelancers are choosing co-working spaces is to establish the reasons that these spaces work for them. At the surface, the freelancer is autonomous in nature, and will work independently often from 
their home. The challenges with this is minimal communication and contact with people from the outside world away from their workspaces. When in an organisation, there is communication and interaction with co-workers, which helps to being networks as well as motivate those who are working within organisations. Co-working spaces are able to bring back this sense of community, without the rigidity and bureaucracy that you will find in organisations (Uda, 2013).

In addition, these spaces also expose people to innovation, as upcoming entrepreneurs and start-ups use them to gain some traction before they are able to open their own premises. Being around innovative and creative people helps other discover ideas on how they can improve themselves and the work that they are doing.

There are numerous definitions that you will find for co-working. One of these is that it occurs at any time there is more than on motivated person that fathers with the intention to work and create shared value for the benefit of the community (Kwiatkowski \& Buczynski, 2011). Another definition comes from Moriset (2013) and it looks at the co-working space as a third space. This basically means that there is a place which is outside the home or office, where people are able to come together and convene and socialize within a free and informal manner (Moriset, 2013). This should not be confused with traditional third places which may simply be places where people are working outside of the office, such as coffee shops and the like.

According to Uda (2013), Co-working may be defined as a "way of working in which working individuals gather in a place to create value while sharing information and wisdom by means of communication and cooperating under the conditions of their choices" (Uda, 2013). He highlights that those who choose to use these spaces are not restricted to working within a particular job or industry, and that they also do not have the space to themselves. They need to share the space with other likeminded individuals.

One more definition of co-working spaces looks at the past understanding of what is was, and is offered by Fost (2008). He claims that those who are using co-working spaces are working on their own, though doing so side by side. (Fost, 2008)

Co-working takes place within a shared and collaborative workspace and there is an emphasis on community, productivity and relationships rather than on the space itself. It is revolutionary and has created a completely new way of working for many people around the world.

Visually, co-working spaces are normally open plan in nature, and within these spaces it is possible to work with other unaffiliated professionals. It is necessary to pay a fee each month to gain access to a large number of services (Spinuzzi, 2012).

\section{Literature Review}

In the year 2008, the world faced an economic crisis that had not been experienced in centuries, the results of which are still being felt in the workplace today (Gandini, 2015). The result of this crisis was a change in the structure of employment, where practices that had once been commonplace were no longer the standard. Rather than most people working within employment structures, people were becoming more individualised within the labour market. The result was that the workforce became more freelance, as well as their being more focus on projects.

Freelancers have increased in number, as have the challenges that they need to overcome to remain productive. Co-working spaces are offering an ideal solution to some of these challenges. Co-working may appear to be a buzzword that is linked with up and coming start-ups or young entrepreneurs. It is much more than that. According to Gandini (2005), one cannot deny that co-working has a firm footing in the creative space and those who are working in knowledge fields.

A study in 2011 (Kwiatkowski \& Buczynski, 2011) reveals that freelancers often operate under the misconception that they can achieve success by working from home on a flexible schedule while working in their pyjamas. They quickly discover that this is not the case, and it is necessary to have some structure. Co-working offers that structure as it facilitates various things. To begin with, it makes it possible for someone to create a structure and timetable that they can follow. This helps with the adequate utilization of time.

Another reason that can cause freelancers to lose out from their work is a lack of social skills. In a co-working space, one needs to interact with a range of people while within the space, which helps develop relationships that can further the freelancer's agenda (Kwaitkowski \& Buczynski, 2014). 
Co-working spaces allow for the creation of a tribe of people that you need, and who need you to help you attain your overall goals. Freelancers find that they can develop and grow within this space without the restrictions that they encounter when they are employed.

\subsection{Growth of Co-Working Around the Globe}

Co-working as a phenomenon has only been in place over the last decade, with the first co-working space being identified in the year 2006. It was set up by a man named Brad Neuberg and he named it the Hat Factory. It was literally set up in what was once a Hat Factory, and offered Brad, and his friends, a place that they could work while in San Francisco (Uda, 2013). His idea continued to grow as the first people within his space, branched out and started creating co-working spaces of their own. The result is that there are co-working spaces that you can now find all over the world.

A study by Moriset (2013) revealed that there were 66 countries that were offering co-working spaces for freelancers, a number that is bound to have increased between then and now. Within theses 66 countries, there were 528 cities with these spaces, and a total of 2,498 spaces which are available. These spaces can be found everywhere, in both developed as well as developing economies. However, it is worth noting that the bulk of the co-working spaces are found in advanced economies.

In the same study by Moriset (2013), there is a critical analysis of the growth and future of co-working. It is assumed that the growth of this type of working is attributed to the recent economic downturn, particularly in North America and Europe. Also, other countries in the world will experience growth in co-working due to increases in bankruptcies, massive layoffs as well as cheap office space. Lower salaries are also contributing to more people seeking to work as freelancers, and in a co-working atmosphere.

The increase of co-working spaces in the future will also mean the increase of all the services and amenities that are offered so that they can remain relevant. For example, most of these places will have a coffee shop, meeting room as well as seminars that can be organized for key groups. These are the same amenities that you will find in a large company. In fact, some companies are also trying to infringe on the co-working space by sponsoring these types of areas within, thereby having an influence on the freelancers who are using these places. The growth of these spaces may also decline in the future as not everyone can become an entrepreneur and achieve success. Innovation is the key reason that many of these businesses are unable to move forward. Instead, it makes more sense for those who are looking to be their own boss (Moriset, 2013).

Research has uncovered that leading companies in Silicon Valley, including Google, Samsung, and Facebook are looking at modelling themselves in the same way that coworking spaces are functioning today. This is because these spaces have proven to spark innovation as well as collaboration more effectively than in the more traditional office setting. The office space is a strategic tool for growth, and there are many companies unearthing the positive results that come out of coworking (Waber, Magnolfi, \& Lindsay, 2014).

\section{Method}

To understand the point of view of different freelancers who are considering co-working as a method to grow and develop themselves, a focus group was put in place to gain essential insight. This focus group was made up of 30 individuals who were required to fit within some specific criteria.

\subsection{Sampling}

The research method that was used was qualitative in nature, to ensure that varied points of view were actively captured during the process of analysis. The total population of freelancers in the United States if 53 million people, based on a study that was carried out in 2014 (Konrad, 2016). This means that a total of 34\% of the workforce are working independently in this country. In the next few years, at least by 2020 , it is expected that this number will shoot up to $50 \%$ of the total workforce. This is also because it is growing by $100 \%$ from one year to the next. Furthermore, there are more companies that are looking at working with independent workers so that they are able to save costs. This is due to the way that the labor environment is being reshaped.

Qualitative analysis makes it possible to find answers to this phenomenon, first hand from the people who are a part of the co-working movement. In addition to providing excellent primary data, it also features results to questions that provide deeper insight into what is happening within the co-working space. 


\subsection{Respondent Profile}

The focus group featured 30 individuals as a representation of the growing number of freelancers across the country. All those who were within the group had freelancing experience, ranging from six months to three years. They were all previously employed and had voluntarily left their work places to go into freelancing. Furthermore, they had not created new business entities as entrepreneurs, rather, they were making the most of co-working spaces in order to elevate their business, earn more money, and increase their net worth.

\subsection{Data Collection Methods}

Data was collecting through a focus group interview. The focus group featured a total of thirty people. During the discussion, all thirty were asked some basic questions and then divided into three groups, each with ten people. The first question and answer session lasted for 15 minutes, and the second question and answer session lasted for 45 minutes, allowing for in-depth sharing.

Responses were recorded and analyzed to identify the common threads between them, and also specific points that stood out as unique and worth discussion. There was also a debate from the respondents that helped them amplify the responses they were sharing within the group. Each focus group had a moderator to guide the questions, and ensure that the respondents remained on track.

\section{Results}

A review of the literature, as well as information from the focus group has revealed that there are significant advantages to making use of a co-working space. The main one is cost management. In a co-working space, you pay a standard rate for the use of specific facilities. This normally gives you access to a space where you are able to work, electricity and a Wi-Fi connection, conference and meeting facilities, beverages and so much more.

It is clear that those who are working within a co-working space are doing more than just being freelancers. They are becoming a part of a community, just as though they would be if they were working within a company. These types of environment also make it possible for workers to unearth and develop their full potential so that they can gain all the power possible when they are working.

A key question that was discussed was the reasons that people are choosing to work as freelancers, rather than remain in employment. This question was the introduction to the next, which set to establish why people are choosing co-working spaces as freelancers. $43 \%$ of the respondents in the focus group stated that they were not satisfied with the working environment, and amongst this percentage, $61 \%$ stated that it was due to them not receiving adequate remuneration. Another $36 \%$ of the respondents stated that they chose freelancing as they were retrenched or let go from their jobs, and the opportunities for employment were scarce. Therefore, to make ends meet they needed to market their own talents. There were a further $12 \%$ of the respondents who cited being their own boss as the primary reason that they chose to become freelancers. The remaining $9 \%$ of them decided to become freelancers as it appeared to be a cool trend and their friends were doing the same.

The reasons for choosing co-working spaces were also diverse, with three key reasons standing out the most. $63 \%$ of the respondents cited convenience as the main reason that they chose to work within a co-working space. This convenience comes from having all the facilities that they need in one place, and not having to pay a high cost to make use of these services. $20 \%$ of the respondents shared that they chose co-working because of the human connections, as it is possible to interact with other like-minded individuals in a setting that was formal in its nature, but informal in the way that people could communicate. $10 \%$ of the respondents cited that the co-working spaces helped them retain their concentration on work, so that they did not lose track of what they were trying to achieve while in these spaces. The last respondents who made up 7\% of the respondents claimed that they preferred these spaces because they were on trend, and ensured.

Another question looked to establish what the preferred amenities within the co-working space were, and what would make one space more attractive for business growth as compared to another space. It was established that having a meeting room was of key importance, as $79 \%$ of the respondents said that they would only choose a space that had one. This was so they would have a place to meet with potential clients for their growth. In addition, a place that featured a coffee station or shop was also important to limit the movement in and out of the facility when one needed some refreshments. Another key feature which $40 \%$ of the respondents liked was the seminar facilities that allowed for group learning and interaction which is excellent for networking. The basic amenities, which every freelancer said was 
essential included a good seating space, access to washrooms, access to high speed internet service and office tools such as printers, and flexibility as to when the facility can be used.

For most of these spaces, a monthly fee needed to be paid to gain access to the facilities, however, if one did not come for a day, then the freelancers preferred if the cost could be carried forward to the following day.

A question was asked to point out the negative aspects of using a co-working space so as to establish how it could be improved. 34\% of the respondents cited the cost of using the space, especially when just starting out and before one can get a client that will help with the management of the bills. The average amount that the respondents paid in a week was $\$ 135$, whereas there were those that spend between $\$ 350$ and $\$ 500$ in a month. Though cheaper than setting up a full business, this cost was still more expensive than having a set up in their homes. There were also $20 \%$ of the respondents who claimed that they sometimes may appear to be unprofessional when they are having a meeting in their co-working space. This is brought to fore by misunderstanding by many people as to what the space represents. Some say that their clients believe the space is for people who are creative looking to interact and spend time with each other, rather than it being a serious place of work where ideas can be hashed out and solutions found.

When asked whether the respondents would consider returning to full time employment so that they could interact with other workers, all of them said that they would not do so. This was because co-working made it possible to have these relationships without having to invest in them or have strings attached due to employment.

\section{Discussion}

\subsection{Summary of Findings}

Freelancers are increasing over time, and there is little to indicate that the trend is going to decline any time soon. There are various reasons for this, although one that appears to stand out significantly is an economical one. Those who are in employment are not satisfied with the condition of work, neither are they satisfied with the remuneration. They feel that they should go into freelancing so that they can be adequately rewarded for using their full potential.

In line with the study that was carried out by Uda (2013), it has been revealed that co-working has two main components that should be considered when looking at future growth and development. The first of these is the worker within the space, the freelancer, and the decisions that guide them into using this space. The second is the space itself, and the features that encourage people to make use of the space. Having an excellent internet connection and not worrying about having to pay any bills is a key driver for those who are looking to use these spaces. There is also a convenience element which has come out strong during the study, and this convenience is tied into the amenities that are available. These two components are what help ensure that the co-working space is a productive one and will give the desired result for those who are using it.

There is no doubt that there are significant benefits that one can experience when they choose a co-working space, though there are also disadvantages that one needs to be aware of. These disadvantages attracted significant debate during the focus group sessions though there was one reason that stood out significantly. That was the cost element, which seems paradoxical as cost was also cited to be a key advantage for those who were looking to use these spaces. The cost of paying for the space was a key disadvantage for many of the freelancers, especially those who were starting out and were unsure that they would make enough money to cater to this bill. This puts freelancers in different spaces when it comes to their needs, especially looking at how much they are able to afford, the number of years that they have been freelancing, and their financial planning to ensure that they are able to achieve a profit. It was revealed that the more time someone spends freelancing, the better they are at managing their expenses and making the most of the space, especially when it comes to co-working.

\subsection{Limitations}

This study was short term and intensive in nature, bringing together freelancers that have been making use of these spaces to achieve results. The key limitation here lies in the members who made up the focus group as they were required to fit within specific criteria as a profile. This included making sure that they were freelancers, who understood and had already made use of co-working spaces. For a more holistic study, it would be ideal to look at freelancers and understand the ways that they make the decision to enter a co-working space, meaning that they can be analysed from before the time they choose the space.

Another limitation was location, as the study focused on what was happening within the United States of America as a base. Studying co-working from other countries in the world and understanding co-working decisions made there would be key to ensuring a clear view is available on the mind-set of the co-worker. 


\subsection{Recommendations for Future Research}

An assessment of the existing literature has revealed that there is a significant gap when it comes to the research and information that is available on co-working. This is one area that requires a critical analysis, especially when it comes to the theoretical application of this topic.

Furthermore, a detailed study should be carried out to establish the duration of time that a freelancer will spend within a co-working space. This could be essential to understanding the overall development within this area, and how these spaces impact their growth. It would be interesting to discover whether once someone has made the best possible use of the space they break off and create their own businesses, or whether they remain as freelancers for the foreseeable future.

\section{References}

Fost, D. (2008, February 20). They're Working on Their Own, Just Side by Side. Retrieved from The New York Times: http://nutopia.us/NYTimes.pdf

Gandini, A. (2015). The rise of coworking spaces: A literature review. Ephemera Theory and Politics in Organization, 15(1), 193-205.

Konrad, M. (2016, May 24). Freelancers Make Up 34 Percent of the U.S. Workforce. Here's How to Find, Hire and Manage Them. Retrieved from Entrepreneur Network: https://www.entrepreneur.com/article/275362

Kwaitkowski, A., \& Buczynski, B. (2014). Coworking: building community as a space catalyst. Cohere, LLC.

Kwiatkowski, A., \& Buczynski, B. (2011). Coworking: How Freelancers Escape the Coffee Shop Office and Tales of Community from Independents Around the World. Fort Collins, Colorado, US: Cohere Coworking.

Moriset, B. (2013). Building new places of the creative economy. The rise of coworking spaces. Hal Archives Ouvertes.

Spinuzzi, C. (2012). Working Alone, Together: Coworking as Emergent Collaborative Activity. Journal of Business and Technical Communication, 26(4), 399-441. https://doi.org/10.1177/1050651912444070

Uda, T. (2013). What is Coworking? : A Theoretical Study on the Concept of Coworking. Discussion Paper, Series A, 265, 1-15. https://doi.org/10.2139/ssrn.2937194

Waber, B., Magnolfi, J., \& Lindsay, G. (2014). Workspaces That Move People. Harvard Business Review. 